\title{
Covid-19 and drug therapy, what we learned
}

\author{
Alessio Provenzani ${ }^{1}\left[\right.$ D $\cdot$ Piera Polidori ${ }^{1}$ \\ Received: 17 March 2020 / Accepted: 27 April 2020 / Published online: 7 May 2020 \\ (c) Springer Nature Switzerland AG 2020
}

\begin{abstract}
COVID-19, the disease associated in December 2019 with the novel coronavirus SARS-CoV-2, was observed for the first time in China and then spread worldwide becoming pandemic. Currently, there is still no licensed specific antiviral treatment for the human coronavirus disease and a vaccine will not be ready soon. However, based on experience from the use of other antiviral agents to treat similar virusses, some treatment options have been tried with some efficacy. Clinical trials for future therapies are still ongoing. In the meantime, prevention, control, active communication and investment in research are the only ways to overcome this challenge.
\end{abstract}

Keywords Antiviral treatment $\cdot$ Coronavirus $\cdot$ COVID-19 $\cdot$ SARS-CoV-2

Since 31 December 2019, COVID-19, the disease associated with the novel coranovirus Severe Acute Respiratory Syndrome Coronavirus-2 (SARS-CoV-2), caused so far thousands of confirmed cases and deaths all over the world [1].

This virus was observed for the first time in Wuhan, China, and very quickly has spread outside Chinese border affecting most of the world becoming no longer an outbreak, but officially a pandemic $[2,3]$.

COVID-19, like the Severe Acute Respiratory Syndrome (SARS) and Middle East Respiratory Syndrome (MERS), belongs to the group of ribonucleic acid (RNA) viruses that circulate among animals with some of them also known to infects humans [4]. These viruses are very common in the world and are so called because of the crown-shaped tips that are present on their surface [5].

Coronaviruses are the largest group of viruses belonging to the Nidovirales order, which includes Coronaviridae, Arteriviridae, and Roniviridae families. The Coronaviridae are further divided into four groups: alpha, beta, gamma and delta coronaviruses [6-9]. SARS-CoV-2, belongs to the beta coronavirus cluster [6].

Currently, there is still no licensed specific antiviral treatment for the human coronavirus disease and a vaccine

Alessio Provenzani

aprovenzani@ismett.edu

1 Department of Clinical Pharmacy, Mediterranean Institute for Transplantation and Advanced Specialized Therapies (ISMETT), Via E. Tricomi n. 5, 90127 Palermo, Italy will not be ready soon. Treatment is therefore based on the patient's symptoms and supportive care $[6,10]$.

So far, although scientific evidence is limited, existing drugs approved for other indications have been used to treat COVID-19 [10].

Based on the proven efficacy against SARS-COV, the second-generation protease inhibitor lopinavir, approved for the treatment of HIV in combination with a low dose of ritonavir to increase its plasma half-life, has been used to treat COVID-19 [10, 11]. However, despite the use of lopinavir/ritonavir in combination with ribavirin was initially considered a promising therapy for treating COVID19 infections [10,11], a recent study comparing a group of patients treated with lopinavir/ritonavir and standard treatment $(n=99)$ versus a second group treated with standard treatment alone $(n=100)$ [12] showed that the use of lopinavir-ritonavir association had no benefit compared to standard treatment alone [12]. The standard treatment was based on the administration of oxygen, invasive and non-invasive ventilation, antibiotics, vasopressor drugs, possible dialysis and extracorporeal oxygenation (ECMO) [12].

However, as reported also by the authors, this study had several limitations, one of all the lack of blindness and inhomogeneity of the arms with respect to some patients characteristics such as the severity of the disease and the onset of baseline symptoms [12].

The results of this study are therefore not transferable to stable patients and with less serious clinical symptoms. 
Other authors suggest that interferon- $\alpha$, a broad spectrum antiviral drug used for the treatment of hepatitis, administered by inhalation is also helpful in inhibiting the virus $[10,13]$.

Also, the last version (7th edition) of the Guidelines for the Prevention, Diagnosis, and Treatment of Novel Coronavirus-induced Pneumonia [14] included as useful therapy, together with the antimalarial chloroquine and the antiviral treatment for influenza arbidol, the broadspectrum antiviral agent Ribavirin, a guanosine analogue used to treat several virus infections like hepatitis $C$ virus, respiratory syncytial virus and viral hemorrhagic fevers. However, for its undesiderable side effect like anemia, the use of ribavirin may not be convenient in patients who are already very compromised such as those with COVID-19 [13-15].

A recent single arm study performed on 20 COVID-19 patients shows that the use of hydroxychloroquine also by adding the antibacterial drug azithromycin is efficient in viral load reduction/disappearance [16]. Hydroxychloroquine and chloroquine's antiviral activity appears to be due to the increase in endosomal ph which is crucial for viruscell fusion $[17,18]$. Azithromycin, in addition to inhibiting the protein synthesis of bacteria, is able to mitigate inflammation and modulate the immune system $[19,20]$.

However, this study has important methodological problems: non-randomized study, small sample size $(n=36)$ and few patients $(n=6)$ treated with azithromycin.

To the contrary, another report on the use of a combination of hydroxicloroquine and azithromycin to treat COVID19 patients showed no evidence of a strong of antiviral activity or clinical benefit from the use of the aforementioned drug association [21].

Very recently some australian researchers demonstrated that ivermectin, an Food and Drug Administration (FDA) approved anti-parasitic, have broad-spectrum anti-viral activity in vitro, with a single dose able to stop viral growth in $48 \mathrm{~h}$ [22]. This effect can be explained by the inhibition of IMP $\alpha / \beta 1$ during infection impacting on cell division [22].

So far, researchers have proposed more than 30 drugs (remdesevir, favipiravir, darunavir/cobicistat, indinavir, saquinavir, carfilzomib, fosamprenavir, bortezomib, raltegravir, raltegravir, etc....) with possible activity against COVID-19 [13, 23, 24].

However, to date, the most promising antiviral drug able to fighting COVID-19 is the nucleotide prodrug remdesivir (GS-5734). This drug, recently involved in four phase III clinical trials in China and United States [25], has a broad spectrum of antiviral activities against RNA viruses like filoviruses, paramyxoviruses, pneumoviruses, SARS and MERS coronavirus [10].

Based on pre-clinical studies in Ebola virus, remdesivir act as an inhibitor of RNA polymerase, thus determining a premature termination of viral RNA transcription $[10,13$, 26].

Animal experiments showed that remdesivir in combination with interferon can reduce the viral load in lung tissue of mice infected with MERS, consequently improving lung function and decreasing damage of the tissue [13].

Other studies suggests that a combination therapy of remdesivir with specific monoclonal antibodies could be the ideal therapeutic option for treat COVID-19 [27, 28].

Tocilizumab, a drug approved by FDA for rheumatoid arthritis and cytokine release syndrome (CRS), seems to be helpful in patients infected with COVID-19. These patients can develop uncontrolled immune response leading to serious life-threatening damage to lung tissue. Tocilizumab is not active against the virus, however, inhibiting the interleukin-6 receptor it could decrease the systemic inflammation (cytokine release storm) and consequently improve the prognosis [29, 30].

Interesting suggestions for future treatments could be the development of type II transmembrane serine protease (TMPRSS2) inhibitors like camostat mesilate, approved in Japan for the treatment of pancreatic inflammation [10]. This drug could act by blocking the entry of the virus inside lung cells and disabling the activation of the spike protein of SARS-CoV [10, 13, 31]. To be fully effective, it need to be used in combination with an Abelson (Abl) kinase inhibitors (i.e. the anticancer imatinib) which inhibits fusion of the virions at the endosomal membrane [10, 13, 31, 32].

Finally, since the SARS-COV-2 uses angiotensin-converting enzyme 2 (ACE2) as the receptor binding domain for its spike protein, some authors hypothesize that angiotensin receptor 1 (AT1R) blockers such as losartan or telmisartan, could have some beneficial in patients infected by COVID19 who experienced pneumonia [33-35].

To the present, there is only one retrospective study suggesting that COVID-19 patients with hypertension and already treated with angiotensin-converting enzyme inhibitors or angiotensin II receptor blockers, showed better clinical outcome with respect to patients treated with other antihypertensive drugs [36].

Still, other authors suggest the opposite. The over-expression of cardiac ACE2 receptors in patients treated with these classes of drugs could expose them more to the virus [37].

As both these hypotheses are still unproven, this matter remains an interesting starting point for future studies.

The challenge that awaits us tomorrow is to understand where we went wrong and if in these years we could have done more. When this pandemic finally will end, we will have to roll up our sleeves and work hard so that such events can no longer happen. If a new threat arises, now we must be prepared.

Currently, none of the drugs on the market is really effective against COVID-19. The new antiviral drugs should 
ensure better pharmacokinetic properties, greater potency and/or a lower toxicity profile than currently available therapies. The combined use of multiple antiviral drugs is the right way to go, so it is possible to increase antiviral activity, reduce the dosage of single drugs (and thus toxicity), and prevent the development of resistance by providing a wider antiviral activity than single drug treatment does. Identifying new molecular targets within the virus is also crucial [37]. The new strategic therapies involve the use of drugs that modulate the host's immune response, drugs that stimulate the immune response, or virus-specific immunotherapies to boost the host's defenses.

Prevention, control, active communication and investment in research are the only ways to overcome this and future challenges that humanity will face. When SARS, MERS or EBOLA spread, scientists started promising research, but when the epidemics finished, they didn't go on and look onward [38]. From now on everything has to change. We must review the functioning and management of animal markets by increasing their safety, since these markets are the main places of origin of new zoonotic pathogens and therefore are high risk areas for public health [2]. We must then understand viruses, their origin and development better.

Search for more effective and safer therapies is humanity's ultimate challenge in the twenty-first century.

Today we really had proof of this.

Funding None.

Conflicts of interest The authors declare that they have no relationships relevant to the contents of this paper to disclose.

\section{References}

1. https://www.ecdc.europa.eu/en/geographical-distribution2019-ncov-cases. Accessed 17 Apr 2020.

2. Malta M, Rimoin AW, Strathdee SA. The coronavirus 2019nCoV epidemic: Is hindsight 20/20? EClinicalMedicine. 2020;20:100289.

3. https://www.who.int/dg/speeches/detail/who-director-general-sopening-remarks-at-the-media-briefing-on-covid-19---11-march -2020. Accessed 13 Mar 2020.

4. Ji W, Wang W, Zhao X, Zai J, Li X. Cross-species transmission of the newly identified coronavirus 2019-nCoV. J Med Virol. 2020;92(4):433-40.

5. Velavan TP, Meyer CG. The COVID-19 epidemic. Trop Med Int Health. 2020;25(3):278-80.

6. Sun P, Lu X, Xu C, Sun W, Pan B. Understanding of COVID-19 based on current evidence. J Med Virol. 2020;92:548-51. https:// doi.org/10.1002/jmv.25722. [Epub ahead of print].

7. Fehr AR, Perlman S. Coronaviruses: an overview of their replication and pathogenesis. Methods Mol Biol. 2015;1282:1-23.

8. Chen Y, Liu Q, Guo D. Emerging coronaviruses: genome structure, replication, and pathogenesis. J Med Virol. 2020;92(4):418-23.
9. Zhu N, Zhang D, Wang W, Li X, Yang B, Song J, et al. A novel coronavirus from patients with pneumonia in China, 2019. N Engl J Med. 2020;382(8):727-33.

10. Martinez MA. Compounds with therapeutic potential against novel respiratory 2019 coronavirus. Antimicrob Agents Chemother. 2020;64:e00399.

11. Chu CM, Cheng VC, Hung IF, Wong MM, Chan KH, Chan KS, et al. Role of LOPINAVIR/ritonavir in the treatment of SARS: initial virological and clinical findings. Thorax. 2004;59(3):252-6.

12. Cao B, Wang Y, Wen D, Liu W, Wang J, Fan G, et al. Trial of lopinavir-ritonavir in adults hospitalized with severe Covid-19. N Engl J Med. 2020. https://doi.org/10.1056/NEJMoa2001282.

13. Dong L, Hu S, Gao J. Discovering drugs to treat coronavirus disease 2019 (COVID-19). Drug Discov Ther. 2020;14(1):58-60.

14. https://www.chinalawtranslate.com/coronavirus-treatment-plan7/?lang=en. Accessed 17 Apr 2020.

15. Zhang Q, Wang Y, Qi C, Shen L, Li J. Clinical trial analysis of 2019-nCoV therapy registered in China. J Med Virol. 2020;92:540-5.

16. Gautret P, Lagier JC, Parola P, Meddeb L, Mailhe M, Doudier $\mathrm{B}$, et al. Hydroxychloroquine and azithromycin as a treatment of COVID-19: results of an open-label non-randomized clinical trial. Int J Antimicrob Agents. 2020. https://doi.org/10.1016/j.ijantimica g.2020.105949.

17. Savarino A, Di Trani L, Donatelli I, Cauda R, Cassone A. New insights into the antiviral effects of chloroquine. Lancet Infect Dis. 2006;6(2):67-9.

18. Devaux CA, Rolain JM, Colson P, Raoult D. New insights on the antiviral effects of chloroquine against coronavirus: what to expect for COVID-19? Int J Antimicrob Agents. 2020. https://doi. org/10.1016/j.ijantimicag.2020.105938.

19. Amsden GW. Anti-inflammatory effects of macrolides-an underappreciated benefit in the treatment of community-acquired respiratory tract infections and chronic inflammatory pulmonary conditions? J Antimicrob Chemother. 2005;55(1):10-211.

20. Kwiatkowska B, Maślińska M. Macrolide therapy in chronic inflammatory diseases. Mediat Inflamm. 2012;2012:636157. https ://doi.org/10.1155/2012/636157.

21. Molina JM, Delaugerre C, Goff JL, Mela-Lima B, Ponscarme $\mathrm{D}$, Goldwirt L, et al. No evidence of rapid antiviral clearance or clinical benefit with the combination of hydroxychloroquine and azithromycin in patients with severe COVID-19 infection. Med Mal Infect. 2020. https://doi.org/10.1016/j.medmal.2020.03.006.

22. Caly L, Druce JD, Catton MG, Jans DA, Wagstaff KM. The FDA-approved drug ivermectin inhibits the replication of SARSCoV-2 in vitro. Antivir Res. 2020. https://doi.org/10.1016/j.antiv iral.2020.104787.

23. https://clinicaltrials.gov/ct2/show/NCT04304053?term $=$ cobicistat $\&$ cond $=$ covid $-19 \&$ phase $=2 \&$ draw $=2 \&$ rank $=1$. Accessed $17 \mathrm{Apr}$ 2020.

24. https://clinicaltrials.gov/ct2/show/NCT04252274?term=cobicistat $\&$ cond $=$ covid $-19 \&$ phase $=2 \&$ draw $=2 \&$ rank $=2$. Accessed $17 \mathrm{Apr}$ 2020.

25. https://clinicaltrials.gov/ct2/results?term=remdesivir \&cond=COVID-19\&phase=2. Accessed 17 Apr 2020.

26. Mulangu S, Dodd LE, Davey RT Jr, Tshiani Mbaya O, Proschan M, Mukadi D, et al. A randomized, controlled trial of Ebola virus disease therapeutics. N Engl J Med. 2019;381(24):2293-303.

27. Malik YS, Sircar S, Bhat S, Sharun K, Dhama K, Dadar M, et al. Emerging novel coronavirus (2019-nCoV)—current scenario, evolutionary perspective based on genome analysis and recent developments. Vet Q. 2020;40(1):68-76.

28. Cohen J. New coronavirus threat galvanizes scientists. Science. 2020;367(6477):492-3. 10.1126/science.367.6477.492

29. Scott LJ. Tocilizumab: a review in rheumatoid arthritis. Drugs. 2017;77(17):1865-79. 
30. Zhang C, Wu Z, Li JW, Zhao H, Wang GQ. The cytokine release syndrome (CRS) of severe COVID-19 and Interleukin-6 receptor (IL-6R) antagonist Tocilizumab may be the key to reduce the mortality. Int J Antimicrob Agents. 2020. https://doi.org/10.1016/j. ijantimicag.2020.105954.

31. Glowacka I, Bertram S, Müller MA, Allen P, Soilleux E, Pfefferle S, et al. Evidence that TMPRSS2 activates the severe acute respiratory syndrome coronavirus spike protein for membrane fusion and reduces viral control by the humoral immune response. J Virol. 2011;85(9):4122-34.

32. Coleman CM, Sisk JM, Mingo RM, Nelson EA, White JM, Frieman MB. Abelson kinase inhibitors are potent inhibitors of severe acute respiratory syndrome coronavirus and middle east respiratory syndrome coronavirus fusion. J Virol. 2016;90(19):8924-33.

33. Sun ML, Yang JM, Sun YP, Su GH. Inhibitors of RAS might be a good choice for the therapy of COVID-19 pneumonia. Zhonghua Jie He He Hu Xi Za Zhi. 2020;43(3):219-22.

34. Lu R, Zhao X, Li J, Niu P, Yang B, Wu H, et al. Genomic characterisation and epidemiology of 2019 novel coronavirus: implications for virus origins and receptor binding. Lancet. 2020;395(10224):565-74.

35. Gurwitz D. Angiotensin receptor blockers as tentative SARSCoV-2 therapeutics. Drug Dev Res. 2020. https://doi.org/10.1002/ ddr.21656. [Epub ahead of print].

36. Meng J, Xiao G, Zhang J, He X, Ou M, Bi J, et al. Reninangiotensin system inhibitors improve the clinical outcomes of COVID-19 patients with hypertension. Emerg Microbes Infect. 2020;9(1):757-60.

37. Goodman \& Gilman. Le basi farmacologiche della terapia. $\mathrm{X}$ Edizione. 2003. Cap.50, pag. 1275.

38. https://time.com/5819965/coronavirus-treatments-research/. Accessed 17 Apr 2020.

Publisher's Note Springer Nature remains neutral with regard to jurisdictional claims in published maps and institutional affiliations. 